\title{
Multiple Signatures of the JC Polyomavirus in Paired Normal and Altered Colorectal Mucosa Indicate a Link with Human Colorectal Cancer, but Not with Cancer Progression
}

\author{
Elena Uleri ${ }^{1}{ }^{\circledR}$, Claudia Piu ${ }^{1} @$, Maurizio Caocci ${ }^{1}$, Gabriele Ibba ${ }^{1}$, Francesca Sanges ${ }^{1}$, \\ Giovanna Pira ${ }^{1}$, Luciano Murgia ${ }^{2}$, Michele Barmina ${ }^{2}$, Simone Giannecchini ${ }^{3}{ }^{\circledR}$, Alberto Porcu ${ }^{2}$, \\ Caterina Serra ${ }^{1}\left(\mathbb{D}\right.$, Antonio M Scanu ${ }^{2}\left(\mathbb{D}\right.$, Maria R De Miglio ${ }^{2}$ and Antonina Dolei ${ }^{1, *(D)}$ \\ 1 Department of Biomedical Sciences, University of Sassari, viale san Pietro 43B, 07100 Sassari, Italy; \\ elenauleri@tiscali.it (E.U.); claudia-piu@tiscali.it (C.P.); maurizio.caocci@yahoo.it (M.C.); \\ G.ibba@gmx.com (G.I.); f.sanges@yahoo.it (F.S.); gpira@uniss.it (G.P.); cserra@uniss.it (C.S.) \\ 2 Department of Experimental Surgery and Medical Sciences, University of Sassari, viable san Pietro 8, \\ 07100 Sassari, Italy; lmurgia@uniss.it (L.M.); michelebarmina@gmail.com (M.B.); alberto@uniss.it (A.P.); \\ scanu@uniss.it (A.M.S.); demiglio@uniss.it (M.R.D.M.) \\ 3 Department of Experimental and Clinical Medicine, University of Florence, viable Morgagni 50, \\ 50134 Florence, Italy; simone.giannecchini@unifi.it \\ * Correspondence: doleivir@uniss.it; Tel.: +39-079228460; Fax: +39-079212345
}

Received: 20 September 2019; Accepted: 25 November 2019; Published: 27 November 2019

\begin{abstract}
The JC polyomavirus (JCV) has been repeatedly but discordantly detected in healthy colonic mucosa, adenomatous polyps, and colorectal cancer (CRC), and proposed to contribute to oncogenesis. The controversies may derive from differences in JCV targets, patient's cohorts, and methods. Studies of simultaneous detection, quantification, and characterization of JCV presence/expression in paired samples of normal/altered tissues of the same patient are lacking. Therefore, we simultaneously quantified JCV presence (DNA) and expression (mRNA and protein) of T-antigen (T-Ag), Viral Protein $1(V p 1)$, and miR-J1-5p in paired normal/altered tissues of CRC or polyps, and from controls. JCV signatures were found in most samples. They increased in patients, but were higher in normal mucosa than in corresponding polyp or CRC lesions. JCV non-coding control region (NCCR) DNA rearrangements increased in CRC patients, also in normal mucosa, thus before the onset of the lesion. A new $\triangle 98 \mathrm{bp}$ NCCR DNA rearrangement was detected. $T$ - $A g$ levels were higher in normal mucosa than in adenoma and adenocarcinoma lesions, but decreased to levels of controls in established CRC lesions. In CRC, miR-J1-5p expression decreased with CRC progression. $V p 1$ expression was not detected. The data indicate a JCV link with the disease, but possible JCV contributes to oncogenesis should occur at pre-polyp stages.
\end{abstract}

Keywords: colorectal cancer; adenomatous polyps; JC polyomavirus; T-antigen; NCCR non-coding control region; oncogenesis

\section{Introduction}

Colorectal cancer (CRC) is the third most common malignancy worldwide, and the second leading cause of cancer deaths [1,2], with a rising incidence at younger ages and some heterogeneity between countries [3]. Both genetic and environmental factors are involved in CRC etiology [3,4], including smoking, alcohol intake, increased body weight, and type-2 diabetes. Worldwide, several independent studies have reported the presence of genomic sequences of the JC polyomavirus (JCV) 
and expression of its potentially oncogenic $\mathrm{T}$-antigen $(\mathrm{T}-\mathrm{Ag})$ protein in tissues from adenomatous polyps and colorectal adenocarcinomas, but also in normal tissues and in adjacent noncancerous tissue from the gastrointestinal tract [5]. At least eight independent groups [5-13] detected JCV signature in CRC (in $28-90 \%$ of the samples) $[5,7,10,14]$, however, negative results were also found $[15,16]$.

Some human polyomaviruses have been associated with cancer. The oncogenic role of the Merkel cell polyomavirus in skin Merkel cell carcinoma has been ascertained, and it is suspected for the BK polyomavirus in bladder carcinoma [17,18], with a possible "hit and run" mechanism [19].

JCV is an opportunistic pathogen [17,20-22], infecting 70-90\% of humans, usually in early childhood, and it persists generally as an innocuous bystander. Primary infection is subclinical; kidneys, B-lymphocytes, and astrocytes may serve as sites for latency. Occasionally, JCV is released in the urine of healthy people or under mild-to-severe immune alterations, as in pregnancy and transplants. Rarely, in severe pathological or therapeutic immunosuppression, JCV infects brain oligodendrocytes lytically, causing the fatal progressive multifocal leukoencephalopathy (PML).

The JCV genome has a regulatory non-coding control region (NCCR), and early and late coding regions, leading, respectively, to the large- $\mathrm{T}$ and small-t antigens (T-Ag and $\mathrm{t}-\mathrm{Ag}$ ), and to the multifunctional agnoprotein (agno) and Viral Protein 1 (Vp1), Viral Protein 2 (Vp2), and Viral Protein 3 (Vp3) capsid proteins [23]. Although JCV replication is restricted to humans, its inoculation in some mammalian species is tumorigenic [22], mainly due to the early antigens. Similarly to simian vacuolating virus 40 (SV40) T-Ag, JCV T-Ag can bind and break DNA, has helicase and ATPase activities, and dysregulates the cell cycle by sequestering the $\mathrm{Rb}$ and $\mathrm{p} 53$ tumor suppressor proteins [22]. The T-Ag translocates IRS-1 to the nucleus, where it interferes with DNA repair fidelity, leading to the accumulation of mutations [24]. Moreover, in cultured colonic cells, JCV increases the AKT and MAPK activities, two pathways involved in tumorigenesis. JCV has been associated with chromosomal instability (CIN) and aneuploidy in tumors. Khalili and colleagues showed that T-Ag interacts with $\beta$-catenin, suggesting that T-Ag stabilizes $\beta$-catenin before loss of tumor suppressor genes, allowing CIN to emerge [22]. Ricciardiello's group showed that in the diploid RKO colon carcinoma cell line, JCV-transient transfection induces chromosomal breakage, di-centric chromosomes, and increased ploidy, with a "hit and run" mechanism that involves an early interaction with $\beta$-catenin and p53 [25]. These features make JCV unique in its ability to simultaneously disrupt chromosomal integrity and abolish cell cycle checkpoints.

The JCV DNA was detected in $90 \%$ of colorectal tumor lesions with respect to $48 \%$ of normal surrounding mucosa, suggesting a selection for virus-containing cells at some early stage in tumor initiation or progression [26]. Recently, JCV DNA was found in $46 \%$ of the adenocarcinomas, but in none of the normal biopsies of either CRC or control patients; moreover, its presence was correlated with tumor location and grade [27]. In another study from the same country, JCV DNA was detected in $58 \%$ of CRC and in $15 \%$ of paired non tumor samples, and JCV presence was significantly correlated with tumor differentiation, as well as accumulation of $\beta$-catenin and p53 [14]. The JCV DNA was detected also in $20-89 \%$ of normal mucosa samples from controls and patients [28,29]. However, JCV DNA copy numbers were higher in tumor mucosa, and JCV proteins were detected only in neoplastic tissues. Several groups also found JCV in brain tumors, as glioblastoma and medulloblastoma [8]; JCV was actively responsible for cell transformation in cell lines obtained from tumors induced by JCV intracranial inoculation in hamsters and transgenic mice [30]. JCV genome and T-Ag have been found in colorectal carcinoma, but also in benign pre-neoplastic polyps, suggesting that JCV may play a role in the early stages of the neoplastic process $[28,29]$. However, other studies did not detect viral genomes, neither in hyperplastic polyps/adenoma and adenocarcinoma, nor in normal adjacent and non-adjacent mucosa $[15,31]$.

In metastatic primary CRC, T-Ag DNA was found in corresponding liver metastasis, and JCV was associated with a metastatic phenotype [32]. These data are supported by an in vitro study, showing increased cell migration when colonic cell lines were transfected with a T-Ag expression plasmid [33]. In this view, one can argue that the presence of viral DNA in colorectal lesions is also associated with 
its previous presence in normal colonic mucosa. A study reported anti-T-Ag immunoreactivity in $46 \%$ of CRC without JCV DNA, concluding that the antibody cross-reacted with an undefined protein, whose expression was associated with chromosomal instability, lymph node metastasis, and a more advanced tumor stage [34]. Another qualitative study showed JCV DNA in $44 \%$ of CRC in the tumor mass (and 35\% also in surrounding tissue), but also in infiltrating lymphocytes [12]. Stromal JCV T-Ag DNA signals in CRC were reported in association with short survival and bad prognosis [35]. Another group detected T-Ag-specific Th-1 cells in all patients with colorectal polyps or cancer, but the Th-1 response in cancer patients was much lower [36].

Of relevance is the discovery of a JCV variant only in colon cancer tissues. JCV exists in two forms: the non-pathogenic archetype, persisting in the kidney, and the PML-type Mad-1 or Mad-4 variants, which were detected in all the aforementioned tumor samples. The difference lies within the NCCR region-the PML-type NCCR contains a duplication of a 98bp sequence, absent in the archetype, which functions as an enhancer for transcription. In a significant number of CRC samples, but not in the adjacent non-neoplastic tissues, the Mad-1 strain of JCV showed a variant with a single 98bp sequence [13].

The JCV-specific miR-J1-5p microRNA (miRNA), which downregulates T-Ag expression [37], was evaluated in healthy and CRC specimens, and detected in all paired CRC and normal tissues, with a prevalence of lower miR-J1-5p levels in tumor tissues [38].

CRC is a global emergency with respect to incidence and mortality; therefore, the possibility of a carcinogenic role of JCV deserves to be clarified.

The published studies on JCV in CRC are discordant, and only few of them analyzed T-Ag expression in paired samples. The controversies may derive, at least in part, from evaluation of different targets, different design, and/or methods. Studies of simultaneous detection, quantification, and characterization of JCV presence/expression in samples of normal/altered tissues of the same patient are lacking. To give insights on JCV role in CRC, we simultaneously analyzed JCV DNA presence and genotype, and the expression of T-Ag, $V p 1$, and miR-J1-5p, in paired normal/altered tissues from patients with CRC and polyps, as well as from controls. Our study is the first to report a complete analysis of JCV signatures in samples of CRC and adenomatous polyp pairs and in non-tumor controls, measuring (i) NCCR and T-Ag DNA, (ii) the expression of T-Ag (mRNA and protein) and $V p 1$, and (iii) miR-J1-5p.

\section{Results}

\subsection{Detection and Analysis of JCV DNA}

We evaluated the T-Ag gene, as it codes for a protein with oncogenic properties, and the NCCR, as it contains the domain prone to variability from which the transcription efficiency depends. We had enough material to examine the DNA of 30 CRC paired samples, 9 polyps, and 9 controls (Table 1 ). As described in the Methods section, the real-time PCR for T-Ag DNA detection was performed on 100 nanograms of each sample, with specific primers and probe, followed by normalization to the glyceraldheyde-3-phosphate dehydrogenase (GAPDH) housekeeping gene. The NCCR sequences were amplified by nested PCR on 200 nanograms of each sample. The amplicons were isolated on agarose gel, purified, and cloned into a cloning vector. Ligation products were used to transform competent cells, and six colonies from each sample were sequenced with the Sanger method. 
Table 1. Clinical and Demographic Features of the Patients, and Summary of Evaluations of the JC Polyomavirus (JCV) DNA, RNA, and Proteins in Mucosal Samples from Non-Tumor Controls (NTC), Polyps, and Colorectal Cancer (CRC) Tissues.

\begin{tabular}{|c|c|c|c|c|c|}
\hline Sample Types & NTC & Polyps & $\begin{array}{l}\text { Paired Polyps and } \\
\text { Adjacent Mucosas }\end{array}$ & \multicolumn{2}{|l|}{ CRC } \\
\hline Mean age \pm SD & $58 \pm 15$ & $64 \pm 8$ & $62 \pm 7$ & \multicolumn{2}{|l|}{$70.3 \pm 9.7$} \\
\hline$n$ Females/Males & $94 / 5$ & $94 / 5$ & $74 / 3$ & \multicolumn{2}{|l|}{$4116 / 25$} \\
\hline Histotype, $n$ & NA, 9 & $\begin{array}{l}\text { Low grade dysplasia, } \\
9\end{array}$ & $\begin{array}{l}\text { Low grade dysplasia, } \\
7\end{array}$ & \multicolumn{2}{|l|}{ Adenocarcinoma, 41} \\
\hline Stage, $n$ & NA & NA & NA & \multicolumn{2}{|l|}{$\begin{array}{c}\text { I, 10; II, } 7 \\
\text { III, 20; IV, } 4\end{array}$} \\
\hline $\begin{array}{c}\text { Mad-1 type } \\
\text { NCCR a }_{n}(\%)\end{array}$ & 9 positive (100) & 9 positive (100) & $\mathrm{nd}^{\mathrm{b}}$ & $\begin{array}{c}\mathrm{N}+/ \mathrm{T}+; 13(44) \\
\mathrm{N}+/ \mathrm{T}-; 4(13) \\
\mathrm{N}-/ \mathrm{T}+; 5(17) \\
\mathrm{N}-/ \mathrm{T}-; 8(26)\end{array}$ & 30 * \\
\hline $\mathrm{T}^{\mathrm{Agg}} \mathrm{DNA}^{\mathrm{c}}, n(\%)$ & 8 positive (89) & 9 positive (100) & nd & $\begin{array}{l}28 \text { positive (93) } \\
2 \text { negative (7) }\end{array}$ & $30 *$ \\
\hline T-Ag RNA ${ }^{\mathrm{d}}, n(\%)$ & nd & nd & 7 positive (100) & $\begin{array}{l}38 \text { positive (95) } \\
3 \text { negative (5) }\end{array}$ & 41 * \\
\hline$V p 1 \mathrm{RNA}^{\mathrm{d}}, n(\%)$ & nd & nd & nd & $\begin{array}{l}41 \text { negative } \\
(100)\end{array}$ & 41 * \\
\hline $\mathrm{T}-\mathrm{Ag}$ protein ${ }^{\mathrm{e}}, n(\%)$ & 9 positive $(100)$ & 9 positive (100) & nd & $\begin{array}{l}15 \text { positive (94) } \\
1 \text { negative (6) }\end{array}$ & $16^{*}$ \\
\hline
\end{tabular}

T-Ag: T-antigen; Vp1: Viral Protein 1; N: normal mucosa; T: tumor mucosa; NA: not applicable; $n$ : number of samples tested; SD: standard deviation. The diagnosis was based on TNM (tumor-node-metastases) staging (stages I, II, III, IV). Detection methods: ${ }^{a}$ non-coding control region (NCCR)-specific nested PCR, followed by sequencing; ${ }^{\mathrm{b}}$ nd: not done, for sample paucity; ${ }^{\mathrm{c}}$ real time PCR; ${ }^{\mathrm{d}}$ real time-RT PCR; ${ }^{\mathrm{e}}$ western blotting; ${ }^{*}$ tested colorectal cancer (CRC) samples (the number of tested samples for each assay was dependent on the amounts available for each sample).

The T-Ag DNA was detected in 93\% of CRC cases (both in tumor and in normal mucosa), in 100\% of polyps, and $89 \%$ of controls (Table 1). As shown on Figure 1, the mean T-Ag levels were 2.4-fold more abundant in normal mucosa than in tumor mucosa $(p=0.02$, Figure $1 \mathrm{~A})$. With respect to individual CRC paired samples, 22 CRC pairs showed reduced levels in the lesion compared to the normal counterpart, whereas eight CRC pairs showed the opposite (Figure 1B, statistical significance: $p=0.009$ by Wilcoxon test for paired samples). No statistically significant association between T-Ag DNA behavior within CRC pairs and clinical stage was observed (not shown).

By NCCR-specific nested PCR, $45 \%$ of CRC cases were positive both in the tumor and in the normal part; $26 \%$ were completely negative and $30 \%$ were positive only in one part. Considering the double-positive CRC cases, and those positive only in one of the two parts, JCV NCCR was found in $74 \%$ of the CRCs tested. All the polyps and the controls tested contained the NCCR region $(100 \%)$ (Table 1).

The NCCR-specific nested PCR produced two types of amplicons (Figure 2A), one of the size of the PML-type (353bp) and a smaller one (260bp). These amplicons were sequenced and compared to NCCR sequences of the NCBI database (accession numbers AB372038.1, NC_001699.1, AB220941.1, AF300953.1), as reported in Figure 2B. All the sequenced samples (22 CRC cases, 9 polyps, and 8 controls) contained a rearranged NCCR of the size and organization typical of the PML-type, with the classical 98bp duplication. 
A

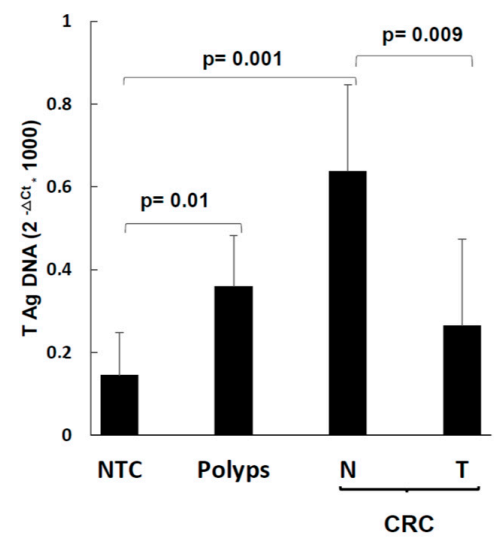

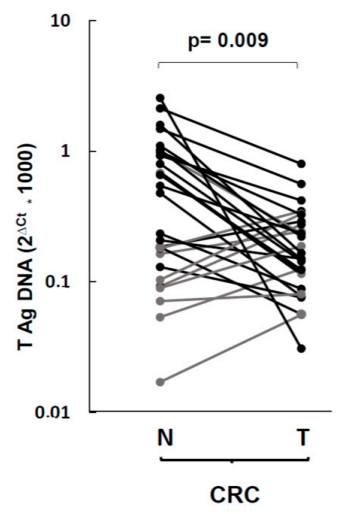

Figure 1. Levels of T-antigen (T- $A g$ ) DNA in NTC, polyps, and CRC tumor and normal surrounding tissues. (A) Mean values of JCV T-Ag DNA copies in NTC, polyps, and CRC tumor (T) and normal (N) surrounding tissues; $(\mathrm{B})$ individual values of JCV T-Ag DNA copies of paired tumor $(\mathrm{T})$ and normal $(\mathrm{N})$ surrounding tissues in CRC cases. Data are expressed according to the $2^{-\Delta C t}$ method [39]. The statistical significance was determined by the two-tailed Student's $t$-test.

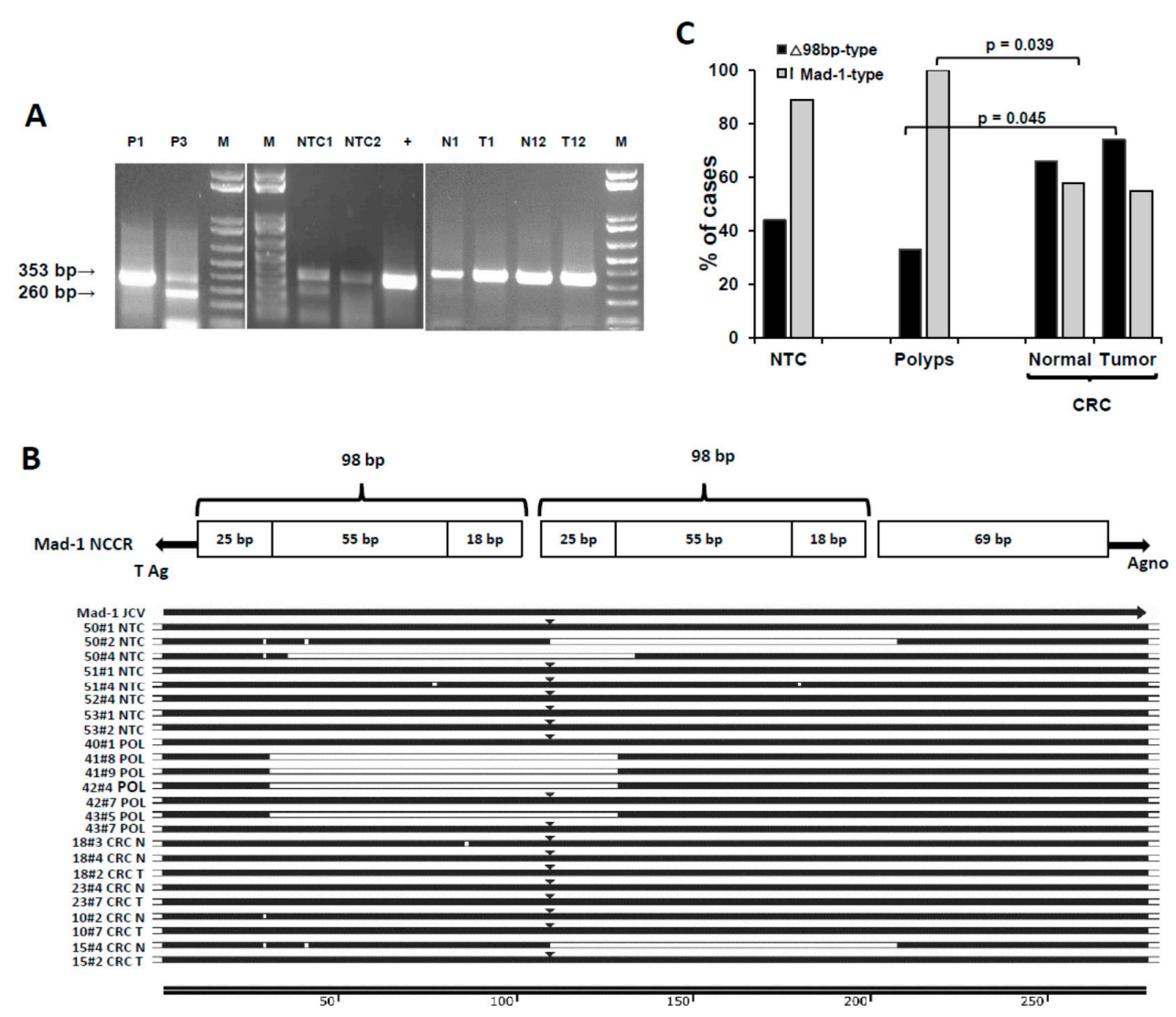

Figure 2. Presence and characterization of the JC polyomavirus (JCV) NCCR DNA in NTC, polyps, and CRC pairs. (A) Migration on agarose gels of representative NCCR amplicons, obtained by nested PCR, as specified in the Methods section. M: marker; +: positive control; NTC: non tumor control; P: polyp; $\mathrm{N}$ : normal adjacent mucosa; T: tumor mucosa. (B) NCCR multiple alignment of sample sequences to JCV strains from the NCBI database. At the top, a schematic representation of the PML-type NCCR organization is reported. (C) Distribution of the Mad-1 prototype and $\triangle 98$ rearranged NCCR forms in NTC, polyps, and CRC, expressed as percentage of cases. See text for details. 
The smaller band was a rearrangement of the NCCR Mad-1PML-type, with a 98bp deletion, which we named $\triangle 98$-type, according to NCCR nomenclature [40]. We observed two types of $\triangle 98 \mathrm{bp}$ rearrangements: a $\Delta 98 \mathrm{a}$ variant (with deletion of the second $98 \mathrm{bp}$ domain), already described in CRC tumor mucosa [13], and a new $\Delta 98 \mathrm{~b}$ rearrangement (with deletion of the first $98 \mathrm{bp}$ domain, and conjunction between the $\mathrm{A}$ region of the first tandem repeat with the $\mathrm{C}$ region of the second one). Figure 2B reports a schematic representation of the PML-type NCCR organization and the alignment to JCV strains from the NCBI database, showing representative sample sequences from controls, polyps, and CRC (four patients each). Point mutations were also detected, mainly in the first A region (where the TATA box is) and in the $C$ region.

We detected the $\Delta 98 \mathrm{bp}$ variants in both healthy and tumor tissues as follows: $74 \%$ of tumor mucosa, $67 \%$ of adjacent mucosa, and $46 \%$ in both. Two CRC cases had only the $\Delta 98 \mathrm{bp}$ variant, one in the adjacent part, the other in the tumor part. Regarding the polyps, $33 \%$ of them also showed the $\triangle 98 \mathrm{bp}$ variant, in addition to the PML-type NCCR, whereas it was present in $44 \%$ of controls. Figure $2 \mathrm{C}$ reports the percent distribution of the NCCR PML-type and $\triangle 98 \mathrm{bp}$ variants in the groups; the latter differed significantly between lesion tissues of CRC and polyps, (two tailed Fisher's exact test, $p=0.045)$.

\subsection{JCV Expression}

The levels of $T-A g$ and $V p 1$ mRNAs were evaluated by RT-real time PCR, as described [39], in $41 \mathrm{CRC}$ and 7 polyp normal/lesion mucosa pairs. The mRNAs were reverse-transcribed and amplified as described in the Methods section. When samples were exposed to real time PCR with $V p 1$-specific primers, no expression of $V p 1$ was detected, as reported in Table 1, indicating the absence of viral replication.

Data of $T-A g$ transcripts in CRC pairs are reported in Figure 3A, and show that T- $A g$ mRNA levels were higher in normal mucosa than in the corresponding tumor part $(p=0.009$, by Wilcoxon test for paired samples). The study of paired polyps and corresponding normal mucosa (left graph of Figure $3 \mathrm{~A}$ ) also revealed that in the normal tissue of patients with polyps, the $T-A g$ was transcribed more than in the corresponding lesion ( $t$-test $p=0.015)$.

To detect the T-Ag protein, which is the functional stage, we performed western blotting analysis of those samples that yielded enough for this assay also ( 16 CRC, 9 polyps, and 9 controls) by using a monoclonal antibody directed against the $\mathrm{N}$-term region of the T-Ag. Representative blots are shown in Figure 3C, which reports the $78 \mathrm{kDa}$ band of T-Ag and the $42 \mathrm{kDa}$ band of the $\beta$-actin housekeeping control. To quantify the T-Ag protein in the bands, and to compare T-Ag levels of CRC, polyps, and controls, a band intensity analysis was performed, as reported in the Methods section.

The data of individual CRC pairs are shown in Figure 3B-as expected from the T- $A g$ mRNA trends, the levels of the T-Ag protein were significantly higher in the normal mucosa than in the lesion (Wilcoxon matched paired test, $p=0.043$ ). Figure 3D reports the normalized T-Ag protein levels of all the groups.

The comparison between the band intensities of controls and polyps showed that the T-Ag expression levels of polyps were 2.3-fold higher than those of the unpaired controls (mean AU (arbitrary units): 0.4 and 0.92, for controls and polyps, respectively, $t$-test $p=0.009$ ), and more scattered. Interestingly, the T-Ag expression levels of normal mucosa of CRC pairs (mean AU: 0.87) were about the same detected in the polyps, whereas the CRC tumor part had a strong T-Ag decrease with respect to the normal part (mean AU: $0.48, p=0.023$ ), almost down to the levels of the controls. 
A

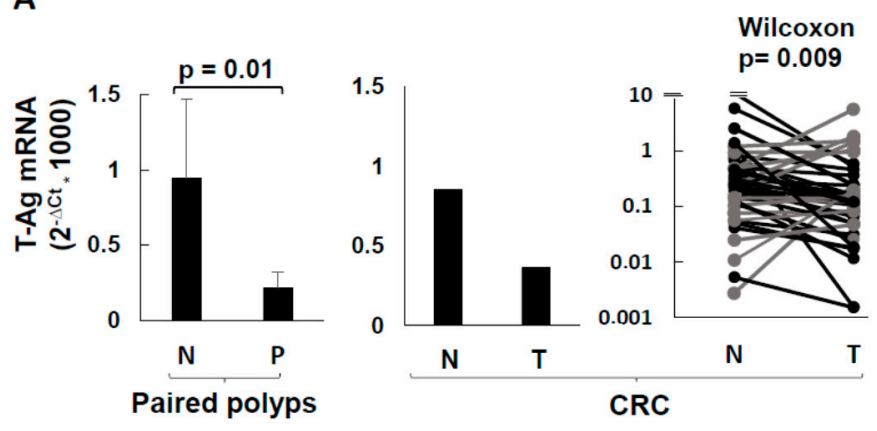

B

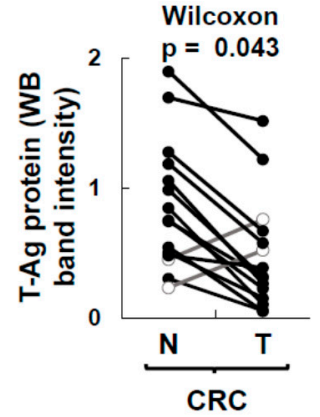

C

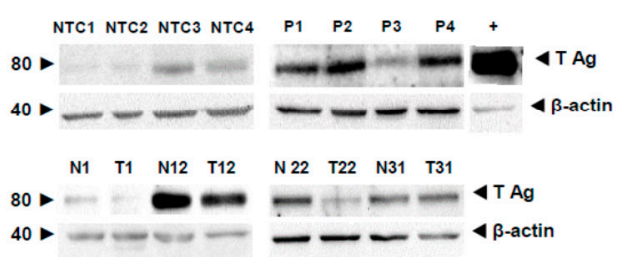

D

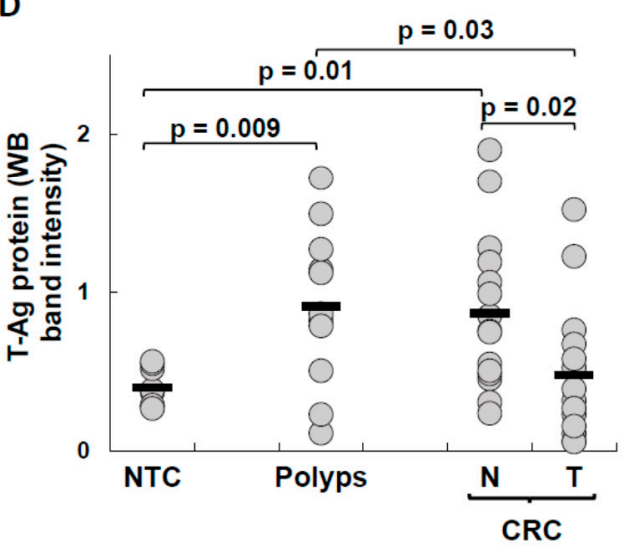

Figure 3. $T-A g$ expression in NTC, polyps, and CRC pairs. (A) Levels of $T$ - $A g$ transcripts in paired adenomatous polyps and CRC cases. (B) Levels of T-Ag protein in CRC for each patient. The gray lines indicate the two samples with higher levels in the lesion than in normal tissue. (C) Western blotting of representative samples from non-tumor controls (NTC), polyps (P), and CRC normal (N) and tumor (T) tissues. (D) Arbitrary quantification of the intensity of relevant bands in western blotting for each sample of NTC, polyps, and CRC. The levels of $T$ - $A g$ transcripts were expressed according to the $2^{-\Delta C t}$ method [39]. The statistical significance was determined by the two-tailed Student's $t$-test in (A) and (D), and by the Wilcoxon signed rank test for paired samples in (B).

\section{3. miR-J1-5p Evaluation}

The miR-J1-5p were analyzed on 39 CRC pairs (Figure 4). In Figure 4A, the data are expressed as tumor/normal $2^{-\Delta C t}$ ratio, showing that $44 \%$ of the CRC lesions expressed lower $m i R-J 1-5 p$ than the normal mucosa from the same patient, whereas $36 \%$ of the pairs showed the opposite; $20 \%$ of the pairs had minor variations. Some of the samples had enough material to be analyzed also for $T-A g$ expression by western blotting, and could allow the comparison of miR-J1-5p levels to those of the $T-A g$ protein, as an inverse relationship between $T-A g$ protein expression and miR-J1-5p occurs during JCV replication [37]. However, only 50\% of CRC cases presented this inverse relationship (Figure 4B). When miR-J1-5p data were compared to T-Ag RNA, DNA, and clinical data, only the correlation with TNM (tumor-node-metastases) staging emerged - the miR-J1-5p tumor/normal ratio decreased with the CRC progression (Figure 4C). 
A

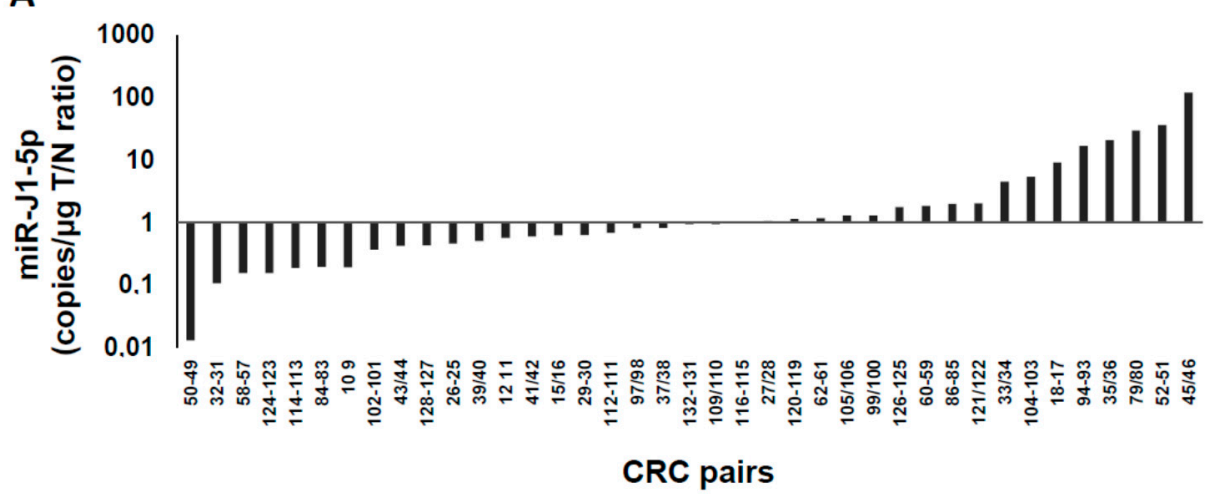

B

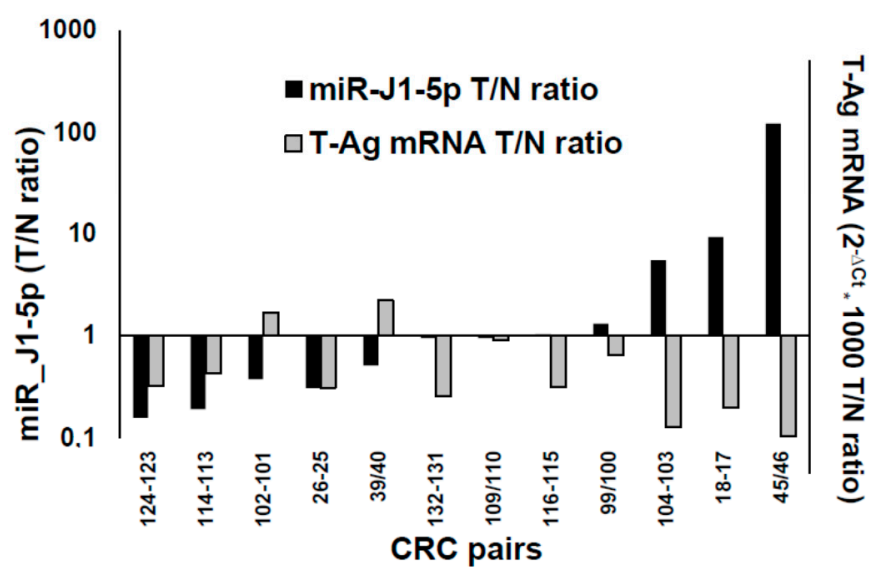

C

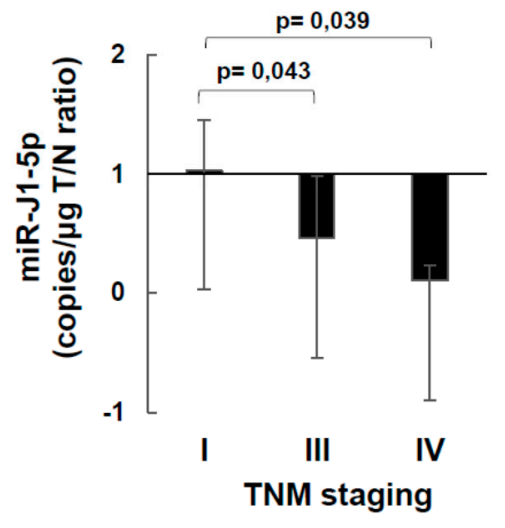

Figure 4. Levels of miR-J1-5p microRNA (miRNA) in CRC pairs. (A) miR-J1-5p values, obtained by a quantitative stem-loop RT-PCR miRNA assay, and expressed as CRC tumor/normal ratio. The values are sorted in ascending order. (B) Relationship among JCV miR-J1-5p miRNA and T- $A g$ expression; the relative miRNA expression in tumor and normal tissues ( $\mathrm{T} / \mathrm{N}$ ratio) is plotted against the corresponding $T-A g$ relative expression, expressed as $\mathrm{T} / \mathrm{N}$ ratio. (C) miR-J1-5p CRC tumor/normal ratios stratified according to CRC TNM staging. The statistical significance was determined by two-tailed Student's $t$-test.

\section{Discussion}

In search of a link between JCV and CRC oncogenesis, many independent studies evaluated JCV presence and/or expression or sero-reactivity in CRC and adenomatous polyps. Altogether, the studies found JCV signature in lesions, in adjacent normal tissues or in non-tumor colorectal mucosa, with discordant findings, attributable, at least in part, to evaluation of different targets, and by different methods; only few studies analyzed paired samples from the same patient $[5,7,10]$.

We performed a multi-parametric analysis of JCV in paired samples of normal and altered mucosa from patients with CRC or polyps, compared also to controls. To our knowledge, it is the first study that simultaneously evaluates and quantifies JCV presence (DNA, the T-Ag, and NCCR regions) and expression (mRNA and proteins, $T-A g$, and $V p 1$ ) in the same sample, and compares pairwise normal and altered tissues from the same individual, thus excluding bias due to variability between individuals, and to different targets and detection methods.

According to our data, $\mathrm{T}-\mathrm{Ag}$ DNA detection in colorectal mucosa is a common finding, occurring in $89 \%$ of controls, $100 \%$ of polyps, and $93 \%$ of CRC cases (Figure $1 \mathrm{~A}$ ). The pairwise analysis gave a new finding - the positivity was in both normal mucosa and lesion, and the few negative pairs were so in both parts. Therefore, it is likely that the local infection occurred before CRC onset. The controls had the lowest T-Ag DNA levels, as one would expect, if JCV has some link to the disease. The T-Ag 
DNA levels of polyps were 2.6-fold higher than controls $(p=0.01)$. However, the highest $T-A g$ DNA levels were observed in the normal mucosa of CRC patients (4.5-fold more than controls, $p=0.001$ ). In turn, the normal mucosa of CRC pairs had 2.4-fold more $T$ - $A g$ DNA than the lesion $(p=0.009)$, even though some CRC pairs showed a slight increase in the tumor part. Because the mean $T-A g$ DNA levels of polyps were similar to those of CRC lesions, one can argue that, after an initial increase, JCV was reduced in tumor tissues. Given the statistically significant differences among the low JCV load of controls and the CRC normal tissues, as well as among polyps and controls, it is possible that a high JCV load could predispose to cell transformation. We are aware that our polyps and controls derive from different individuals and cannot be representative of the adenoma tumor progression.

To our knowledge, this is the first report of higher JCV DNA levels in normal compared with corresponding CRC mucosa, and the data are confirmed by those of mRNA and protein expression (see below). By real-time PCR, Newcomb et al. [15] did not find any JCV positivity in matched CRC tumors. By nested PCR of serial dilutions from paired samples, Laghi et al. [28] found higher levels in CRC tissues, with 26-89\% positivity depending on the method used. By simple or nested PCR, Toumi et al. [27] found JCV DNA exclusively in tumors (46\%), but not in normal mucosa, and hypothesized differences among patients from different countries. By simple PCR, Casini et al. found 89\% JCV/BKV positivity in Italian CRC patients, mostly in both tumor and normal mucosa [12], whereas no JCV DNA was found in Italian CRC patients by Campello et al. [31] by real-time quantitative PCR. According to us, Italian individuals behave as other cohorts.

In a report on gastric cancer, JCV T-Ag DNA of both cancer tissues and paired adjacent normal parts was 10-fold higher than in normal gastric patients [41].

In our study, the positivity for NCCR and T-Ag DNAs was the same in controls and polyps, whereas, in overall CRC, it was $74 \%$ for NCCR and $93 \%$ for $T-A g$. This discordance could be intrinsic to the virus and/or the disease stage, or might be due to the different methods used.

Two types of NCCR amplicons were observed (Figure 2A): one of the size of the PML-type (369bp) and a smaller one (270bp). By sequencing, the higher band was found to be the expected PML-type Mad-1 prototype. The lower band was a Mad-1 variant, with two types of rearrangements. The $\Delta 98$ a rearrangement, with deletion of the second 98bp domain, has been observed in CRC tumor mucosa [13], in kidneys and brains of infected patients [42], and in bone marrow and brain tissue from a PML patient [43]; a construct with this rearrangement was shown to transform Rat-2 fibroblasts more efficiently than the Mad-1 prototype [44]. We found also a new $\Delta 98 \mathrm{~b}$ rearrangement (Figure 2B). Functionally, the two forms should behave similarly, as they share the same binding sites for transcription factors.

Although the Mad-1 prototype prevailed in controls and polyps, the rearranged forms were increased in CRC normal and lesion samples (polyps versus CRC lesions: $p=0.045$, Figure 2C). DNA rearrangements are expected during oncogenesis. However, because NCCR rearrangements were increased also in CRC normal mucosa, the data suggest that the NCCR rearrangements preceded the CRC transformation and thus could be a feature of persons who develop CRC.

The analysis of the transcriptional activity of JCV genes did not detect expression of $V p 1$ in CRC pairs, indicating the lack of JCV replication in colonic cells from these patients.

$T-A g$, instead, was actively expressed both as mRNA and protein (Figure 3). The present study is the first quantifying $T-A g$ expression at both levels, and pairwise. In both polyp and CRC pairs, the mean $T-A g$ mRNA levels were 2.4-fold higher in the normal mucosa than in the lesion. In the 16 CRC pairs, which yielded enough in amount to allow protein analysis, the levels of the T-Ag protein were consistent with those of transcripts. Importantly, the levels of the T-Ag protein, which is the most relevant JCV protein for a contribution to oncogenesis, varied with disease status in a statistically significant manner. The lowest levels were those of the controls, as one would expect. In polyps, the values of T-Ag protein were more than twice those of controls. Interestingly, the $T-A g$ expression levels of normal mucosa of CRC pairs were about the same detected in the polyps, whereas the CRC tumor part had a strong $T-A g$ decrease with respect to the non-lesion part and to polyps, almost down 
to the levels of the controls. There have been only four studies that have analyzed T-Ag protein presence in colorectal mucosa, all by immunostaining of formalin-fixed, paraffin-embedded samples from lesions, without the corresponding normal mucosa. Three of them analyzed polyps, and found $0 \%$ [35], 5\% [45], and 16\% [29] positivity. Two studies analyzed CRC samples, finding $0 \%$ [35] and $65 \%$ [46] positivity.

Our data indicate that $T-A g$ expression is measurable in almost all samples, with wide variations among individuals ( $\sim 4$ logs at the mRNA level, and $\sim 2.5$ logs at the protein level). The high sensitivity was primarily due to the fact that freshly excided tissues were analyzed, and because, to detect the T-Ag protein by western blot, proteins from many cells were collected, thus amplifying the signal. By immunostaining, instead, only cells expressing high amounts of protein can be detected.

The T-Ag protein was shown to induce chromosomal instability in colonic cells, with early inactivation of $\mathrm{p} 53$ and $\mathrm{Rb}$ tumor suppressors, dysregulation of signaling pathways, and interference with DNA repair $[22,25,47]$. Therefore, our findings are in line with the possibility of a "hit and run" mechanism of JCV contribution to cell growth dysregulation and chromosomal instability. According to this model, a pre-existing JCV infection is associated with the early stages of cell growth alterations, but it is no more needed for the progression when additional mutations render T-antigen expression dispensable.

JCV miRNAs have been proposed as a biomarker for JCV infection in the gastrointestinal tract [38]. In CRC pairs, we found expression of JCV-specific miR-J1-5p in normal and tumor mucosa of all samples tested (Figure 4), with both lower and higher expression in the tumor part, with respect to normal mucosa from the same patient, in line with previous data [38]. JCV miR-J1-5p, produced during late transcription, controls viral replication through $T-A g$ downregulation and targeting of host factors, helping JCV to escape the immune surveillance [37,48]. In our study, only $50 \%$ of CRC cases had the inverse relationship between $T-A g$ protein and $m i R-J 1-5 p$, which occurs during JCV replication [37], indicating that in colonic cells and in a tumor environment, the expected $T-A g$ regulation by JCV miRNA does not occur. When miR-J1-5p data were stratified with respect to the TNM staging of the disease (Figure 4C), the tumor/normal ratio decreased with CRC progression, indicating that $m i R-J 1-5 p$ levels decrease more in tumor than in normal mucosa (at stage $\mathrm{I}$, there were almost equal amounts in both, whereas at stage IV, the lesion had only 1/10 miR-J1-5p levels of normal mucosa).

The main conclusions of the present study are that (i) JCV infection of colorectal mucosa is much higher than expected. (ii) JCV is linked to colorectal disease, as viral presence (DNA) and expression (mRNA and protein) change with levels in normal adjacent mucosa higher than in the lesion of the same individual, concordantly and in a statistically significant manner, in controls and in patients with polyps or CRC. JCV NCCR rearrangements increase in CRC individuals, also in normal mucosa, thus before the onset of the neoplastic lesion. (iii) $T$ - $A g$ presence and expression occur before the onset of the adenoma and adenocarcinoma lesions, as $T-A g$ levels are higher in the normal adjacent mucosa than in the lesion, but go down to the levels of controls in already established CRC lesions. (iv) The relative reduction of miR-J1-5p expression in CRC lesions is related to CRC progression.

\section{Materials and Methods}

\subsection{Patients}

Fresh samples from 41 CRC adenocarcinoma patients, 16 with adenomatous polyps, and 9 non-tumor controls (NTC) were obtained from the General Surgery Unit-2, Department of Clinical and Experimental Medicine, University of Sassari. The study was approved by the Bioethics Committee of the Azienda Sanitaria Locale Sassari, Italy (\# 2032/CE, 13.05.2014), and all participants gave informed consent. Paired samples from the lesion and from adjacent normal mucosa $(7-10 \mathrm{~cm}$ faraway, without any sign of alteration) were obtained from all the CRC patients, and from seven of the polyp cases. The tumors were classified according to the TNM (tumor-node-metastases) staging [49]. Demographic and clinical-pathological data are reported in Table 1 . The samples were processed within 1-2 $\mathrm{h}$ 
from excision. Depending on the amounts available, each sample was divided in up to four parts for DNA, RNA, and protein extraction. To preserve RNAs and proteins, the corresponding aliquots were stored in RNA-Later (Thermo-Fisher Scientific, Inc., Waltham, MA, USA) at $+4{ }^{\circ} \mathrm{C}$ overnight. Then, the RNA-Later was removed, and the samples were transferred at $-80^{\circ} \mathrm{C}$. The samples for DNA extraction were stored dry at $-80^{\circ} \mathrm{C}$.

\subsection{DNA Analysis}

DNA extraction was carried out with DNeasy Blood and Tissue Kits, according to the manufacturer's instructions (Qiagen, Hilden, Germany). Enough tissue amounts for this assay were available for 30 CRC pairs, 9 polyps, and 9 controls. The real-time PCR for T-Ag DNA detection was performed on $100 \mathrm{ng}$ of each sample, as published [50]. Two-hundred ng of DNA were used to detect JCV NCCR by nested PCR, as published [51]. Five microliters of the first PCR product served as template for nested PCR. The amplicons were analyzed by electrophoresis on $1 \%$ agarose gel. The 353bp band and the lower band were excised from the gel; the DNA was purified by PureLink Quick Gel Extraction and PCR Purification Combo kit (Thermo-Fisher Scientific, Inc., Waltham, MA, USA) and cloned using TA cloning kit for sequencing (Life Technologies, Eugene, OR, USA) [42]. Ligation products were used to transform DH5 $\alpha$ Escherichia coli competent cells. DNA was extracted from colonies by miniprep kit (Qiagen, Hilden, Germany). From each sample, six colonies were sequenced with the Sanger method [52].

\subsection{RNA Analysis}

After mechanical dissociation, normal/lesional pairs from 41 CRC and 7 polyps were processed with miRNeasy Mini Kit, according to manufacturer's instructions (Qiagen, Hilden, Germany). The mRNAs were enriched, using the Dynabeads mRNA kit (Dynal Biotech, Oslo, Norway). For each mRNA sample, $1 \mu \mathrm{g}$ was reverse-transcribed, as published [53]. Real-time PCR with specific primers and probes for $T-A g$ [50] and $V p 1$ were used [54]. To verify the proper mRNA extraction and reverse-transcription outcomes, validated internal controls were used [53]. As positive JCV control, DNA from transiently transfected SW480 cells was used [39]. For each sample, the Ct (cycle threshold) value of the gene of interest was normalized to that of the glyceraldheyde-3-phosphate dehydrogenase (GAPDH) housekeeping gene; the data were expressed according to the $2^{-\Delta \mathrm{Ct}}$ method [55].

The expression of miR-J1-5p was measured by the specific JCV miRNA-J1-5p quantitative stem-loop RT-PCR MiRNA assay (Assay ID 007464_mat, Life Technologies, Foster City, CA, USA), according to the manufacturer's protocol. The reaction was performed in triplicate by using $10 \mathrm{ng}$ of each RNA, and included negative controls (no template) and synthetized oligonucleotides as standards. The specificity and reproducibility of the assay has been published [37].

\subsection{Protein Analysis}

Enough tissue for this study was available for 16 CRC pairs, 9 polyps, and 9 controls. Whole cell extracts were obtained after lysis with Ripa Buffer (Thermo-Fisher Scientific, Inc., Waltham, MA, USA) and mammalian protease inhibitor cocktail (Roche, Basel, Switzerland), as described [53]. Western blot was performed as published [53], with anti-SV40 T-Antigen PAb416 monoclonal antibody (Merck KGaA, Darmstadt, Germania), diluted 1:200. As loading control, the $\beta$-actin protein was evaluated using mouse anti- $\beta$-actin monoclonal antibody (Sigma-Aldrich, Buchs, Switzerland), diluted 1:5000. Secondary antibody was horseradish peroxidase-conjugated IgG antibody, diluted 1:15,000 (Thermo-Fisher Scientific, Inc., Waltham, MA, USA). The membranes were developed with a chemoluminescent substrate (Supersignal West Femto Maximum Sensitivity Substrate; Thermo-Fisher Scientific, Inc., Waltham, MA, USA), exposed to Molecular Imager VersaDoc 3000 (BioRAD, Hercules, CA, USA), and acquired by QuantityOne Software (BioRAD, Hercules, CA, USA), as published [39]. The band intensities were evaluated through the Image 1.51.S software [56]. 


\subsection{Statistics}

Descriptive analysis included the computation of means, standard deviations, and $t$-test for independent samples or Wilcoxon signed-rank test to compare related samples. Linear regression tests (Pearson's test) were performed to quantify the strength of relationship between targets and variables.

Author Contributions: Conceptualization, A.D. and E.U.; methodology and validation, E.U., C.P., and C.S.; formal analysis, A.D. and E.U.; investigation, E.U., C.P., M.C., G.I., F.S., G.P., L.M., M.B., S.G., A.P., C.S., A.M.S., M.R.D.M., and A.D.; resources, A.M.S., A.P., C.S., and C.P.; data curation, A.D. and E.U.; writing-original draft preparation, A.D. and E.U.; writing-review and editing, A.D.; supervision, A.D.; project administration, C.S.; funding acquisition, A.D.

Funding: This research was funded in part by Regione Autonoma Sardegna (LR72012DOLEI), and Fondazione Italiana Sclerosi Multipla (2016_R_12).

Acknowledgments: E.U. and A.D. share the last authorship. We are grateful to G. Delogu and E. Manca for their excellent technical assistance.

Conflicts of Interest: The authors declare no conflict of interest.

\section{Abbreviations}

$\begin{array}{ll}\text { Agno } & \text { Agnoprotein } \\ \text { AU } & \text { Arbitrary units } \\ \text { CIN } & \text { Chromosomal instability } \\ \text { CRC } & \text { Colorectal cancer } \\ \text { GAPDH } & \text { Glyceraldheyde-3-phosphate dehydrogenase } \\ \text { JCV } & \text { JC polyomavirus } \\ \text { miRNA } & \text { microRNA } \\ \text { NCCR } & \text { Non-coding control region } \\ \text { PML } & \text { Progressive multifocal leukoencephalopathy } \\ \text { RT } & \text { Reverse transcriptase } \\ \text { T-Ag } & \text { T-antigen } \\ \text { TNM } & \text { Tumor-node-metastases } \\ \text { VP1 } & \text { Viral Protein 1 }\end{array}$

\section{References}

1. Yang, T.; Li, X.; Montazeri, Z.; Little, J.; Farrington, S.M.; Ioannidis, J.P.A.; Dunlop, M.G.; Campbell, H.; Timofeeva, M.; Theodoratou, E. Gene-environment interactions and colorectal cancer risk: An umbrella review of systematic reviews and meta-analyses of observational studies. Int. J. Cancer 2019, 145, 2315-2329. [CrossRef]

2. Siegel, R.L.; Miller, K.D.; Fedewa, S.A.; Ahnen, D.J.; Meester, R.G.S.; Barzi, A.; Jemal, A. Colorectal cancer statistics. Cancer J. Clin. 2017, 67, 177-193. [CrossRef]

3. Keum, N.; Giovannucci, E. Global burden of colorectal cancer: Emerging trends, risk factors and prevention strategies. Nat. Rev. Gastroenterol. Hepatol. 2019, 27, 1-20. [CrossRef]

4. Kuipers, E.J.; Grady, W.M.; Lieberman, D.; Seufferlein, T.; Sung, J.J.; Boelens, P.G.; van de Velde, C.J.; Watanabe, T. Colorectal Cancer. Nat. Rev. Dis. Primers 2015, 1, 15065. [CrossRef] [PubMed]

5. Delbue, S.; Comar, M.; Ferrante, P. Review on the role of the human Polyomavirus JC in the development of tumors. Infect. Agents Cancer 2017, 12, 10. [CrossRef]

6. Hampras, S.S.; Viscidi, R.P.; Helzlsouer, K.J.; Lee, J.H.; Fulp, W.J.; Giuliano, A.R.; Platz, E.A.; Rollison, D.E. Prospective Study of Seroreactivity to JC Virus T-Antigen and Risk of Colorectal Cancers and Adenomas. Cancer Epidem. Biomar. 2014, 23, 2591-2596. [CrossRef]

7. Chen, H.; Chen, X.Z.; Waterboer, T.; Castro, F.A.; Brenner, H. Viral infections and colorectal cancer: A systematic review of epidemiological studies. Int. J. Cancer 2014, 137, 12-24. [CrossRef]

8. Del Valle, L.D.; Khalili, K. Detection of human polyomavirus proteins, T-antigen and agnoprotein, in human tumor tissue arrays. J. Med. Virol. 2010, 82, 806-811. [CrossRef] 
9. Rollison, D.E.; Helzlsouer, K.J.; Lee, J.H.; Fulp, W.; Clipp, S.; Hoffman-Bolton, J.A.; Giuliano, A.R.; Platz, E.A.; Viscidi, R.P. Prospective Study of JC Virus Seroreactivity and the Development of Colorectal Cancers and Adenomas. Cancer Epidem. Biomar. 2009, 18, 1515-1523. [CrossRef]

10. Paoli, P.D.; Carbone, A. Carcinogenic viruses and solid cancers without sufficient evidence of causal association. Int. J. Cancer 2013, 133, 1517-1529. [CrossRef]

11. Hori, R.; Murai, Y.; Tsuneyama, K.; Abdel-Aziz, H.O.; Nomoto, K.; Takahashi, H.; Cheng, C.M.; Kuchina, T.; Harman, B.V.; Takano, Y. Detection of JC virus DNA sequences in colorectal cancers in Japan. Virchows Arch. 2005, 447, 723-730. [CrossRef] [PubMed]

12. Casini, B.; Borghese, L.; Del Nonno, F.; Galati, G.; Izzo, L.; Caputo, M.; Perrone Donnorso, R.; Castelli, M.; Risuleo, G.; Visca, P. Presence and incidence of DNA sequences of human polyomavirus BKV and JCV in colorectal tumor tissues. Anticancer Res. 2005, 25, 1079-1086. [PubMed]

13. Ricciardiello, L.; Chang, D.K.; Laghi, L.; Goel, A.; Chang, C.L.; Boland, C.R. Mad-1 Is the Exclusive JC Virus Strain Present in the Human Colon, and Its Transcriptional Control Region Has a Deleted 98-Base-Pair Sequence in Colon Cancer Tissues. J. Virol. 2001, 75, 1996-2001. [CrossRef] [PubMed]

14. Ksiaa, F.; Allous, A.; Ziadi, S.; Mokni, M.; Trimeche, M. Assessment and biological significance of JC polyomavirus in colorectal cancer in Tunisia. J. Buon. 2015, 20, 762-769.

15. Newcomb, P.A.; Bush, A.C.; Stoner, G.L.; Lampe, J.W.; Potter, J.D.; Bigler, J. No evidence of an association of JC virus and colon neoplasia. Cancer Epidem. Biomar. 2004, 13, 662-666.

16. Sarvari, J.; Mahmoudvand, S.; Pirbonyeh, N.; Safaei, A.; Hosseini, S.Y. The Very Low Frequency of Epstein-Barr JC and BK Viruses DNA in Colorectal Cancer Tissues in Shiraz, Southwest Iran. Pol. J. Microbiol. 2018, 67, 73-79. [CrossRef]

17. Santos-Juanes, J.; Fernández-Vega, I.; Fuentes, N.; Galache, C.; Coto-Segura, P.; Vivanco, B.; Astudillo, A.; Martínez-Camblor, P. Merkel cell carcinoma and Merkel cell polyomavirus: A systematic review and meta-analysis. Brit. J. Derm. 2015, 173, 42-49. [CrossRef]

18. Moens, U.; Krumbholz, A.; Ehlers, B.; Zell, R.; Johne, R.; Calvignac-Spencer, S.; Lauber, C. Biology, evolution, and medical importance of polyomaviruses: An update. Infect. Genet. Evol. 2017, 54, 18-38. [CrossRef]

19. Levican, J.; Acevedo, M.; León, O.; Gaggero, A.; Aguayo, F. Role of BK human polyomavirus in cancer. Infect. Agents Cancer 2018, 13, 12. [CrossRef]

20. Assetta, B.; Atwood, W.J. The biology of JC polyomavirus. Biol. Chem. 2017, 26, 839-855. [CrossRef]

21. Enam, S.; Gan, D.D.; White, M.K.; Del Valle, L.; Khalili, K. Regulation of Human Polyomavirus JCV in colon cancer. Anticancer Res. 2006, 26, 833-841.

22. Khalili, K.; Valle, L.D.; Otte, J.; Weaver, M.; Gordon, J. Human neurotropic polyomavirus, JCV and its role in carcinogenesis. Oncogene 2003, 22, 5181-5191. [CrossRef] [PubMed]

23. White, M.K.; Safak, M.; Khalili, K. Regulation of Gene Expression in Primate Polyomaviruses. J. Virol. 2009, 83, 10846-10856. [CrossRef] [PubMed]

24. Lassak, A.; Valle, L.D.; Peruzzi, F.; Wang, J.Y.; Enam, S.; Croul, S.; Khalili, K.; Reiss, K. Insulin Receptor Substrate 1 Translocation to the Nucleus by the Human JC Virus T-antigen. J. Biol. Chem. 2002, 277, 17231-17238. [CrossRef]

25. Ricciardiello, L.; Baglioni, M.; Giovannini, C.; Pariali, M.; Cenacchi, G.; Ripalti, A.; Landini, M.P.; Sawa, H.; Nagashima, K.; Frisque, R.J.; et al. Induction of chromosomal instability in colonic cells by the human polyomavirus JC virus. Cancer Res. 2003, 63, 7256-7262.

26. Coelho, T.R.; Gaspar, R.; Figueiredo, P.; Mendonça, C.; Lazo, P.A.; Almeida, L. Human JC polyomavirus in normal colorectal mucosa, hyperplastic polyps, sporadic adenomas, and adenocarcinomas in Portugal. J. Med. Virol. 2013, 85, 2119-2127. [CrossRef]

27. Toumi, W.; Ripalti, A.; Ricciardiello, L.; Cherif, A.; Gargouri, D.; Bouhafa, A.; Kharrat, J.; Jarboui, S.; Benrhouma, H.; Zili, M.; et al. Detection of a new JCV strain of genotype A in a subpopulation of colorectal adenocarcinomas in Tunisia. New Microbiol. 2017, 40, 99-106.

28. Laghi, L.; Randolph, A.E.; Chauhan, D.P.; Marra, G.; Major, E.O.; Neel, J.V.; Boland, C.R. JC virus DNA is present in the mucosa of the human colon and in colorectal cancers. Proc. Natl. Acad. Sci. USA 1999, 96, 7484-7489. [CrossRef]

29. Jung, W.T.; Li, M.S.; Goel, A.; Boland, C.R. JC virus T-antigen expression in sporadic adenomatous polyps of the colon. Cancer 2008, 112, 1028-1036. [CrossRef] 
30. Uleri, E.; Beltrami, S.; Gordon, J.; Dolei, A.; Sariyer, I.K. Extinction of Tumor Antigen Expression by SF2/ASF in JCV-Transformed Cells. Genes Cancer 2011, 2, 728-736. [CrossRef]

31. Campello, C.; Comar, M.; Zanotta, N.; Minicozzi, A.; Rodella, L.; Poli, A. Detection of SV40 in colon cancer: A molecular case-control study from Northeast Italy. J. Med. Virol. 2010, 82, 1197-2100. [CrossRef] [PubMed]

32. Sinagra, E.; Raimondo, D.; Gallo, E.; Stella, M.; Cottone, M.; Orlando, A.; Rossi, F.; Orlando, E.; Messina, M.; Tomasello, G.; et al. Could JC virus provoke metastasis in colon cancer? World J. Gastroenterol. 2014, 20, 15745. [CrossRef] [PubMed]

33. Link, A.; Shin, S.K.; Nagasaka, T.; Balaguer, F.; Koi, M.; Jung, B.; Boland, C.R.; Goel, A. JC Virus Mediates Invasion and Migration in Colorectal Metastasis. PLoS ONE 2009, 4, e8146. [CrossRef] [PubMed]

34. Chiaravalli, A.M.; Longhi, E.; Vigetti, D.; Stefano, F.I.D.; Deleonibus, S.; Capella, C.; Solcia, E.; Parravicini, C. Gastrointestinal cancers reactive for the PAb416 antibody against JCV/SV40 T-Ag lack JCV DNA sequences while showing a distinctive pathologic profile. J. Clin. Pathol. 2012, 66, 44-49. [CrossRef]

35. Samaka, R.M.; El-Wahed, M.M.A.; Aiad, H.A.; Kandil, M.A.; Al-Sharaky, D.R. Does JC virus have a role in the etiology and prognosis of Egyptian colorectal carcinoma? Apmis 2012, 121, 316-328. [CrossRef]

36. Butcher, L.D.; Garcia, M.; Arnold, M.; Ueno, H.; Goel, A.; Boland, C.R. Immune response to JC virus T antigen in patients with and without colorectal neoplasia. Gut Microbes 2014, 5, 468-475. [CrossRef]

37. Martelli, F.; Giannecchini, S. Polyomavirus microRNAs circulating in biological fluids during viral persistence. Rev. Med. Virol. 2017, 27, e1927. [CrossRef]

38. Link, A.; Balaguer, F.; Nagasaka, T.; Boland, C.R.; Goel, A. MicroRNA miR-J1-5p as a potential Biomarker for JC Virus Infection in the Gastrointestinal Tract. PLoS ONE 2014, 9, e100036. [CrossRef]

39. Uleri, E.; Ibba, G.; Piu, C.; Caocci, M.; Leoni, S.; Arru, G.; Serra, C.; Sechi, G.; Dolei, A. JC polyomavirus expression and bell-shaped regulation of its SF2/ASF suppressor during the follow-up of multiple sclerosis patients treated with natalizumab. J. Neurovirol. 2016, 23, 226-238. [CrossRef]

40. Ault, G.S.; Stoner, G.L. Human polyomavirus JC promoter/enhancer rearrangement patterns from progressive multifocal leukoencephalopathy brain are unique derivatives of a single archetypal structure. J. Gen. Virol. 1993, 74, 1499-1507. [CrossRef]

41. Murai, Y.; Zheng, H.C.; Aziz, H.O.A.; Mei, H.; Kutsuna, T.; Nakanishi, Y.; Tsuneyama, K.; Takano, Y. High JC virus load in gastric cancer and adjacent non-cancerous mucosa. Cancer Sci. 2007, 98, 25-31. [CrossRef] [PubMed]

42. Elsner, C.; Dörries, K. Human polyomavirus JC control region variants in persistently infected CNS and kidney tissue. J. Gen. Virol. 1998, 79, 789-799. [CrossRef] [PubMed]

43. Jensen, P.N.; Major, E.O. Viral variant nucleotide sequences help expose leukocytic positioning in the JC virus pathway to the CNS. J. Leukoc. Biol. 1999, 65, 428-438. [CrossRef]

44. Bollag, B.; Chuke, W.F.; Frisque, R.J. Hybrid genomes of the polyomaviruses JC virus, BK virus, and simian virus 40: Identification of sequences important for efficient transformation. J. Virol. 1989, 63, 863-872. [PubMed]

45. Selgrad, M.; Koornstra, J.J.; Fini, L.; Blom, M.; Huang, R.; Devol, E.B.; Boersma-van, E.K.W.; Dijkstra, G.; Verdonk, R.C.; de Jong, S.; et al. JC virus infection in colorectal neoplasia that develops after liver transplantation. Clin. Cancer Res. 2008, 14, 6717-6721. [CrossRef] [PubMed]

46. Ripple, M.J.; Parker Struckhoff, A.; Trillo-Tinoco, J.; Li, L.; Margolin, D.A.; McGoey, R.; Del Valle, L. Activation of c-Myc and Cyclin D1 by JCV T-Antigen and $\beta$-catenin in colon cancer. PLoS ONE 2014, 9, e106257. [CrossRef] [PubMed]

47. Niller, H.H.; Wolf, H.; Minarovits, J. Viral hit and run-oncogenesis: Genetic and epigenetic scenarios. Cancer Lett. 2011, 305, 200-217. [CrossRef]

48. Lagatie, O.; Loy, T.V.; Tritsmans, L.; Stuyver, L.J. Viral miRNAs in plasma and urine divulge JC polyomavirus infection. Virol. J. 2014, 11, 158. [CrossRef]

49. Lea, D.; Håland, S.; Hagland, H.R.; Søreide, K. Accuracy of TNM staging in colorectal cancer: A review of current culprits, the modern role of morphology and stepping-stones for improvements in the molecular era. Scand. J. Gastroenterol. 2014, 49, 1153-1163. [CrossRef]

50. Delbue, S.; Tremolada, S.; Elia, F.; Carloni, C.; Amico, S.; Tavazzi, E.; Marchioni, E.; Novati, S.; Maserati, R.; Ferrante, P. Lymphotropic Polyomavirus is detected in peripheral blood from immunocompromised and healthy subjects. J. Clin. Virol. 2010, 47, 156-160. [CrossRef] 
51. Boldorini, R.; Caldarelli-Stefano, R.; Monga, G.; Zocchi, M.; Mediati, M.; Tosoni, A.; Ferrante, P. PCR detection of JC virus DNA in the brain tissue of a 9-year-old child with pleomorphic xanthoastrocytoma. J. Neurovirol. 1998, 4, 242-245. [CrossRef] [PubMed]

52. Sanger, F.; Coulson, A. A rapid method for determining sequences in DNA by primed synthesis with DNA polymerase. J. Mol. Biol. 1975, 94, 441-448. [CrossRef]

53. Uleri, E.; Mei, A.; Mameli, G.; Poddighe, L.; Serra, C.; Dolei, A. HIV Tat acts on endogenous retroviruses of the W family and this occurs via Toll-like receptor 4. Aids 2014, 28, 2659-2670. [CrossRef] [PubMed]

54. Uleri, E.; Regan, P.; Dolei, A.; Sariyer, I. SF2/ASF binding region within JC virus NCCR limits early gene transcription in glial cells. Virol. J. 2013, 10, 147. [CrossRef] [PubMed]

55. Mameli, G.; Madeddu, G.; Mei, A.; Uleri, E.; Poddighe, L.; Delogu, L.G.; Maida, I.; Babudieri, S.; Serra, C.; Manetti, R.; et al. Activation of MSRV-Type Endogenous Retroviruses during Infectious Mononucleosis and Epstein-Barr Virus Latency: The Missing Link with Multiple Sclerosis? PLoS ONE 2013, 8, e78474. [CrossRef] [PubMed]

56. Rueden, C.T.; Schindelin, J.; Hiner, M.C.; DeZonia, B.E.; Walter, A.E.; Arena, E.T.; Eliceiri, K.W. ImageJ2: ImageJ for the next generation of scientific image data. BMC Bioinform. 2017, 18, 529. [CrossRef] [PubMed]

(C) 2019 by the authors. Licensee MDPI, Basel, Switzerland. This article is an open access article distributed under the terms and conditions of the Creative Commons Attribution (CC BY) license (http://creativecommons.org/licenses/by/4.0/). 